\title{
The Design and Development of Network Teaching Platform Based on Moodle Task Drive Type
}

\author{
Xia Yaowen \\ Institute of Information \\ Yunnan Normal University \\ Kunming,Yunnan Province,China \\ xywen_km@sina.com
}

\begin{abstract}
This paper firstly analyzes the Moodle platform based on task driven network learning platform building concept, idea, method, strategy; Then based on the strong function of Moodle, make full use of Moodle platform and the characteristics of the task driven teaching in network environment, the application of advantages, design a low cost and high availability network teaching platform, and to our country culture education teachers for experimental class, the network course application in practice, has obtained the certain experimental data, in order to achieve the expected design effect.
\end{abstract}

Keywords- Moodle, Network Teaching Platform, Task Driven, The Teaching System, Teaching Activities

\section{INTRODUCTION}

\section{A. Moodle platform overview}

Moodle all called Modular Object your Dynamic Learning Environment, Chinese translation for Modular object-oriented Dynamic Learning Environment, our country also, it is the "magic lamp" [1]. It is based on a social constructivism development concept and design of the course management system (CMS), it can be used as a traditional classroom teaching course aided and supplement, also can make a completely based on the network course. It can be in almost any kind of support PHP computer platform installation, it interface is simple, operation efficiency, good compatibility, stable performance, simple operation. In a Moodle platform most users can build thousands of door of different network course, and at the same time, the administrator can to different course classification, convenient and quick backup and restore all courses. Dr. Martin Dougiamas Moodle by Australian creative development. 21 August 2002, he issued a Moodle first version: Moodle 1.0, Moodle1.0 edition is aimed at university courses designed and developed. Along with the version of the constantly updated, more elements is injected into the Moodle, Moodle version also constantly change, to October 2010, Moodle version 2.0 release. Now, Moodle users from the university gradually spread to primary and secondary schools, companies, institutions and even the family which. According to the data provided by the Moodle.org by January 2011 so far, the world has a total of Moodle registered sites, 49854, located in 212 countries, providing course 4238093 doors, about 40117412 users[2].

\section{B. The mission driving type teaching outline}

The mission driving type teaching (TBL, Task Based Learning) is a recently developed comparative scientific teaching method; it is in the constructivism learning theory on the basis of probing into type teaching method set up. The mission driving type teaching is that the students in the task of driving and under the guidance of teachers, using the necessary learning resources, through the use of questions, solving the problem of autonomous learning way to acquire knowledge of the process[3]. it is a kind of in recent years has been paid attention to teaching method is one of the professor operation class skills, more suitable for professor computer skills. The mission driving is closely linked to the teacher will study life practical teaching task into the construction of teachers' learning situation, students complete the task of teachers set to learn knowledge teaching. The teacher in the past the classroom teaching, mainly through oral way of teaching content, teaching in paper form to test students' learning outcomes, teaching method, teaching means are very conservative. In this kind of education, teachers and students are very clear boundaries: teachers cramming actively carry out professor; students passive accept teachers impart knowledge. This kind of teaching method is difficult to play to students' subjective initiative, students just a passive, forced memory, for the purpose of the knowledge and using the method of knowledge is not known. Ask questions, to solve the question is the starting point of the teaching task drive type. Let the students in practice learning knowledge, will learn knowledge application in practice. Its foothold is arousing the students' study interest; stimulate students to use the original knowledge to solve new problems of passion. In the task drive type teaching process, the teacher teaching content and the life of a combined, proposed the student to solve the task, to create a suitable for the cultivation of students' autonomous learning practical problem situation, students in this situation, the analysis question, solve the problem of learning knowledge, but also through the team cooperation, and gradually solve the problem, the students in this situation, to learn knowledge and practical problems closely to train the students themselves through the existing knowledge to solve practical problems encountered in life. A kind of practical problems and tasks than boring knowledge for motivating students to learn the effect of will be bigger. 


\section{TEACHING LINK BASED ON THE TASK DRIVEN}

Based on the task driven teaching are discussed. Based on the task driven teaching generally by the following link composition:

\section{A. The task of creating the situation}

First the teacher wants to teach the course according to the nature and content to decide whether this course is suitable for task drive type teaching, if suitable for task drive type teaching, can according to this course in the actual work application, create more knowledge to cover all the tasks set situation. Each task with real life situation and the application consistent, let students to solve problems and accomplish the task has a kind of sense of be personally on the scene. The task is to create the situation of task driving type teaching first step, the task of creating situation is proper, directly affect students' learning effect.

\section{B. In each task context extract task problem}

In each task situation teachers also choose the study progress and the current consistent and closely related to the subject and study the authenticity of the event or problem as the main content of study, and make students in each task situation are all faced with a need to solve the actual problem. Because the teacher will have the course content skillfully create the task situation [4], in general, if let students directly in the face of each task situation, they may not know you really want to solve practical problems, so it is necessary to what is in this link, the mission of extraction, this link role image that is "anchor".

\section{Teachers guide students to complete the task independently}

In the mission, the teacher is not directly tell students should how to solve the problems faced by the mission, he can only provide students to solve the problem about clues. For example, a teacher show students the one web site navigation bar, let the students to check the effect of the navigation bar, and then analyses the navigation bar is how to realize, there are several possible technology can achieve the effect of navigation. If use script code can write the effect of navigation, with Flash can be done before this navigation effect and then will Flash files embedded in web pages, etc. Guide to here, let the students to collect relevant script and Flash material, to complete the task of the follow-up process. Students complete the task in the process if there are some technical problems can always ask the teacher.

So the task driven teaching pay special attention to the cultivation of students' autonomous learning ability, namely:

- $\quad$ to determine the content of the independent learning ability;

- independent access to the information and data ability;

- independent use and evaluation of relevant information and data ability.

- $\quad$ the ability of cooperative learning.

\section{Task performance evaluation and assessment}

The task driven teaching mode and the traditional teaching mode difference also is the evaluation and assessment method. Because the student's learning process is to solve the problem of task process, so this kind of learning style is best for the student to complete the assessment in the process of tracking performance, recording and evaluation, and not fully independent learning process for outside. This kind of evaluation methods mainly effect on the students in the process of task attendance, attitude, work, task means, task, and other comprehensive. The implementation process as shown in figure 1 :

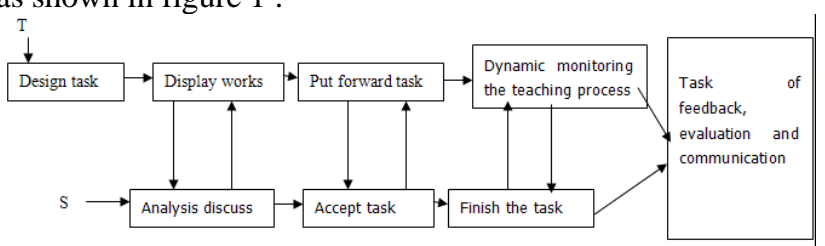

Figure 1. The task driven teaching flowchart

\section{NETWORK TEACHING PLATFORM DESIGN BASED ON THE MOODLE PLATFORM AND TASK DRIVE}

\section{A. Teaching resources}

For network learning speaking, the design of teaching resources is the most important teaching activities, rich, Shared platform resources are successful teaching safeguard. Moodle platform offers a variety of resources to present the way, the author use of resource way, based on the theme of the needs of learners task provides abundant learning resources, and carry on the detailed group and named. Effective integration of resources to provide students with good learning support, reduce the blindness of the students, save the students' precious time. Through the investigation and analysis found that learners subject consciousness is poorer, lack of network learning interest, most of the students' learning is passive [5], therefore, aiming at the students' learning characteristic, the task driven teaching strategy, so as to improve the students' network learning enthusiasm, initiative, the cultivation of students' autonomous inquiry ability. Teachers with target elaborate design learning tasks, and through the teacher assigns tasks, students construct their own knowledge and skills. The student to complete the task process is a constant questions and problem solving process. Therefore, the task of designing a teacher should be left to the student the full analysis and thinking space, space to explore, communication and development space, etc., and this task will have certain challenging, can stimulate students' interest in learning, to produce the motivation of complete the task. In the motivation and interest drive off, realize the inquiry learning, so as to cultivate students' independent inquiry ability. Also make sure that each of the practice of the project can meet the students' sense of accomplishment. 


\section{B. Teaching activities}

Learners the acquisition of knowledge, skills enhancement as well as the emotional attitude change are they and network teaching content of interaction, attributed to them and between learners, and the interaction between teachers. Therefore, this kind of interaction is called the learners' learning activities.

This course of study activity overall design to drive manners through the corresponding task design, implementation, to achieve the ultimate goal of network teaching. Therefore, active task design is a creative design, high quality activity task can not only improve the students' interest in learning, improve students' advanced thinking ability training, and promote the acquisition of knowledge and skills training, and at the same time, improve the students' application ability of knowledge and skill.

In addition, teachers can accord to demand in Moodle platform to create discussion, wiki, blog and collaborative communication tool, and carry out students' positive discussion. Based on a theme of discussion, students can achieve the purpose of problem solving, deepen the understanding of knowledge. In the discussion of the entire process, the teacher give timely guidance, avoid student branch out. Students have problems can timely through the discussion to answer, in the process of the communication not only broaden their field of vision, arouse their interest in learning, and improve their problem solving ability, cooperation ability, etc.

\section{NETWORK TEACHING PLATFORM DESIGN BASED ON THE MOODLE PLATFORM AND TASK DRIVE}

\section{A. Based on the Moodle platform task drive teaching}

Task driven teaching process is the teacher, students, task three positive interaction. Teachers' leading role and students' main body role is interactive. Teachers design the reasonable task, ring bad phase buckle teaching process, promote the students to play a main role in the initiative to complete the various tasks, And the student's main body function more fully, you will find more problems when the problem cannot be solved, turn to teachers, turn to others, at this time, teachers are students, can promote the further play the leading role. Leading promoting subject, main body, promote the leading to complete the whole teaching. Task as the teachers and students interaction intermediary, promote the whole classroom teaching [6][7].

Use Moodle platform for the teaching design, also is in accordance with the teaching goals, teaching contents, learners' levels and different learning environment design suitable course. The theory of Moodle more consideration is the student as the main body, advocate is a kind of to users as the main body of the teaching design concept. And the task driven teaching emphasize that the task Settings, teachers' personal experience, individual performance, self design. The teaching idea of Moodle platform pass, and the task driven teaching idea supplement each other, the task driven teaching Moodle platform for teaching design provides the theoretical support: Moodle platform for the task driven teaching provide practical security. Common reflect "task for open line, in order to cultivate the students' knowledge and skills for concealed, teachers as the led, take the student as the main body" of the double main mode.

\section{B. Based on Moodle task drive teaching platform to realize}

Based on the Moodle platform, based on national culture education curriculum as an example, the above task drive related theory to design, develop a suitable YuGuoPei teachers learning based on task driven network learning platform. This platform has been published 202.203.225.26:8080 / moodle, system operation six months, the system runs stably, the teachers and students reflect good. System main interface as shown in figure 3 shows:

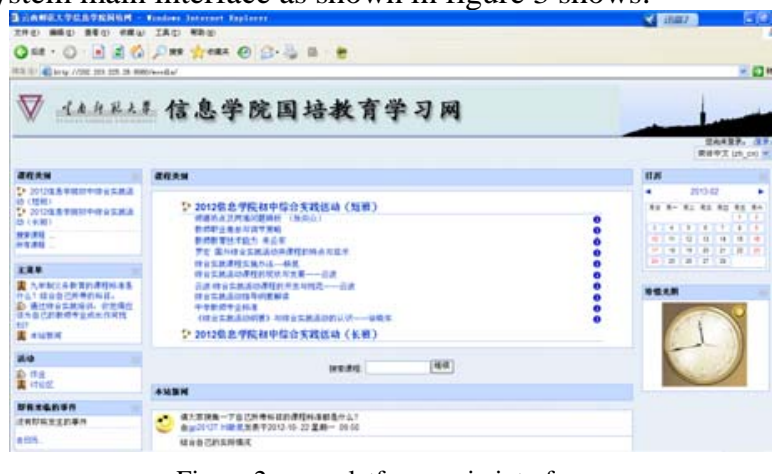

Figure 2. platform main interface

The network teaching platform combined with the task driven teaching idea, the system provides simple operation interface, front desk major provides students with learning support services, provide background management support, including curriculum management module is the core of the whole system, reflect the task driven teaching idea.

\section{CONCLUSIONS}

At present the school curriculum teaching process the prevalence of resource scarcity, pressed for time, evaluation system is not perfected, student participation is not enough, and many other problems, these problems may also influence the information technology curriculum goal the realization, and Moodle platform provides us with a kind of solutions. Based on the Moodle platform of information technology network course design and teaching application, can realize the advantages of network teaching. In this paper, through the introduction of open source software Moodle, provide a low cost and high availability of information technology network teaching plan, let the school can use economic way of building the network platform based on Moodle learning environment, the shortage of the traditional auxiliary existing course. Based on Moodle platform and task drive teaching of information technology network curriculum design and teaching application examples, the application for the future teachers Moodle design and development of information technology network curriculum and teaching, which can be used as a reference for the school established based on Moodle platform network course and on the basis of the implementation of network teaching to use for reference. 


\section{ACKNOWLEDGMENT}

This work is supported by the National NSF of China (No.60903131), the key project of the Education Bureau Youth Fund of Yunnan Province (No.07Z1066).

\section{REFERENCES}

[1] Li Jiahou. Moodle course design [M]. Shanghai: Shanghai education press, 2007.

[2] Moodle community [OL]. http://moodle.org

[3] Lei Junhu. Based on task driven Java practice teaching model [J] Journal of stream: 2009(8):119

[4] Liu Chengxin. Network curriculum design, development and evaluation [J].journal of remote education.2001 : 51 a 52.

[5] Zhong Dapeng, etc., the mission driving method in information technology teaching in the study[J].journal of the foundation Education research ", 2010

[6] Deng Guomin. Based on the Moodle "modern education technology" development and application of the network course [D]. Sichuan normal university Learn. 2008.4

[7] Wu Chuping. Based on the Moodle "modern education technology" teaching design research [D]. Jiangxi normal university. 2008. 